
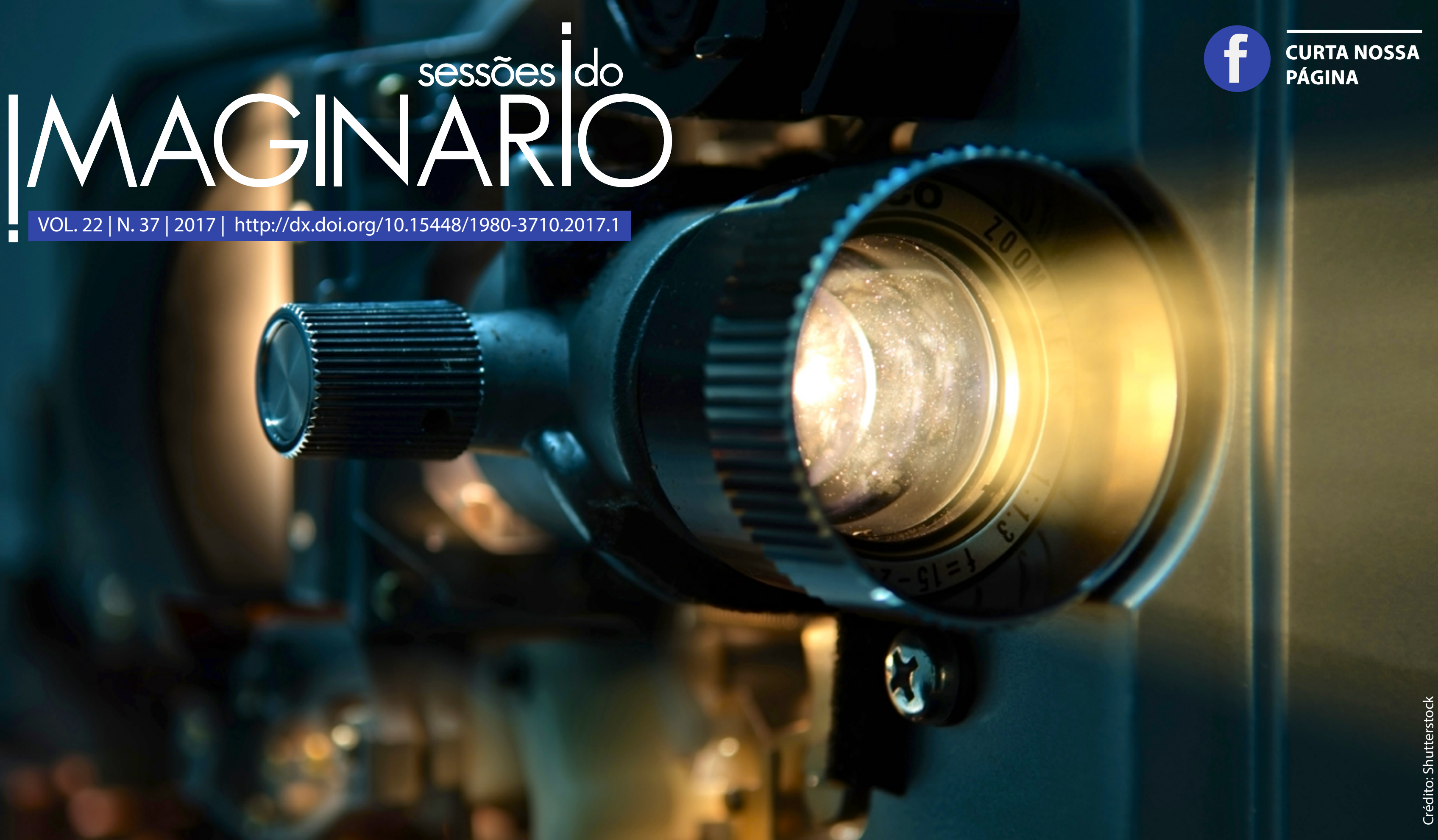

A Comunicação Móvel e Ubíqua do Instagram

Eduardo Campos Pellanda e Melissa Streck
O choque do real em Azul é a cor mais quente

Otacílio Amaral Filho, Sérgio do Espírito Santo Ferreira Júnior e Tarcízio Macedo
A luta de classes em Que Horas ela Volta?

Mayara Luma Assmar Correia Maia Lobato 


\section{A ressignificação da luta de classes: um olhar sócio-histórico sobre Que Horas ela Volta?}

\section{The reinterpretation of the class} struggle: a social-historical perspective on Que Horas ela Volta?

Mayara Luma Assmar Correia Maia Lobato' ${ }^{\top}$

\section{Resumo}

Neste artigo, pretende-se traçar um paralelo histórico entre questões do fim do século XVIII e dos primeiros anos do século XXI, a partir da observação da narrativa do filme Que Horas ela Volta? A produção retrata a imbricada relação, profissional e afetiva, que envolve o trabalho doméstico no Brasil e as atuais transformações socioeconômicas que o país vive. O objetivo é demonstrar que, assim como no passado, quando a burguesia ascendeu e gerou incômodo na aristocracia, hoje a nova classe média começa a ocupar diferentes espaços na vida social, gerando conflitos que se refletem, também, nas representações do cinema contemporâneo. Com base em autores como Hobsbawm, Elias, Berman, Moretti e Veblen, propõe-se um paralelismo entre dois momentos históricos, que salta aos olhos ao examinarmos a construção dos personagens da obra.

\section{Palavras-chave}

Comunicação; cinema; história; transformações sociais; nova classe média brasileira.

\section{Abstract}

In this article, we intend to make a historical parallel between issues of the late 18th century and of early years of the 21st century, through the analysis of the narrative of the movie Que Horas ela Volta?. The production portrays the complicated relationship, professional and emotional, involving domestic work in Brazil, and the current socio-economic transformations that the country is experiencing. The goal is to demonstrate that, as in the past, when the bourgeoisie rose and affected aristocra$c y$, today the new middle class begins to occupy different spaces in society, generating conflicts that are reflected also in the representations of contemporary cinema. Based on authors like Hobsbawm, Elias, Berman, Moretti and Veblen, we propose a parallel between two historical moments, that becomes evident by examining the construction of the film's characters.

\section{Keywords}

Communication; cinema; history; social transformations; new brazilian middle class.

|MAGINARRIOO 


\section{Introdução}

A partir de 1789, o mundo europeu começou a passar por mudanças profundas em suas estruturas sociais, econômicas e culturais, por conta dos acontecimentos ligados à Revolução Francesa. Seu início se dá com a queda da Bastilha, prisão que era o símbolo do poder absolutista francês, e o período de maior instabilidade segue até 1848 , conforme apontado pelo historiador Eric Hobsbawm (1988). A França, junto com a Inglaterra, era a maior potência mundial; por isso, seus eventos tinham consequências significativas no continente europeu e em outras partes do mundo.

Entre as várias mudanças trazidas pela Revolução Francesa, estava a ascensão de uma nova classe social, econômica e política, a burguesia, cujo crescimento foi ajudado também pela Revolução Industrial, que tomou forma na Inglaterra no mesmo período. A classe antes dominante, a aristocracia, agora estava acompanhada dos burgueses e se via perdendo a cada dia seus privilégios. Hobsbawm (2010) ilustra bem esses acontecimentos quando explica o surgimento de um novo ofício entre os séculos XVIII e XIX, o de gastrônomo, que eram os antigos cozinheiros que a aristocracia não conseguia mais manter e abriam restaurantes, frequentados por qualquer um que pudesse pagar, sem depender de convite.

Não eram apenas os cozinheiros que se tornavam raros nas casas aristocráticas: toda uma sorte de empregados - ou criados, como se costumava chamar - escasseavam, como lacaios, damas de companhia, valets e até mordomos. $\mathrm{O}$ mundo mudava com a ascensão de uma nova classe, que tinha outros costumes e impunha novidades àquela sociedade. Manter muitos empregados e grandes propriedades também se tornava cada vez mais caro - e isso dificultava a vida que a aristocracia levara até então. Além de tudo isso, a importância dada aos títulos de nobreza e aos sobrenomes não havia desaparecido, mas perdia espaço diante de um elemento que à burguesia não faltava: 0 dinheiro.

Cerca de dois séculos se passaram desde então. Em muitas esferas, o mundo mudou; em outras, nem tanto. Já não se pode falar em sociedades divididas entre aristocratas e burgueses - pelo menos não no sentido original do termo, por assim dizer -, embora seus valores ainda estejam amplamente presentes. É exatamente isso o mais interessante: conseguir encontrar paralelos entre o período das revoluções Francesa e Industrial e o nosso tempo. Assim como naquele período a burguesia ascendia, hoje, assistimos ao crescimento do que se convencionou denominar como "nova classe média". Assim como a aristocracia, a classe dominante de hoje, em muitos aspectos, se incomoda com as mudanças sociais e se vê, também, perdendo privilégios.

Em suma, em um exercício interpretativo, a burguesia, outrora ascendente, pode ser colocada, hoje, no lugar da classe dominante - e a nova classe média ocupa o espaço que, dois séculos atrás, era o da burguesia. E são essas mudanças trazidas pelas novas configurações sociais que pretendemos estudar neste artigo a partir de um percurso histórico, com base em autores como Berman (2008), Elias (2001), Hobsbawm (1988, 2007), Moretti (2014) e Veblen (1965), que nos ajuda a traçar um paralelo entre o mundo de fins do século XVIII e o atual, aplicando-o à análise das representações de um Brasil em transformação que é representado nas telas do cinema.

Tomamos, como objeto de estudo, o filme Que horas ela volta? (Anna Muylaert, 2015), que retrata a sociedade brasileira a partir da história de uma empregada doméstica, sua filha e a imbricada relação - em diversos aspectos: profissional, pessoal, afetiva - mantida com a família para a qual a protagonista trabalha. Para este estudo, o filme se mostra interessante por explorar as mudanças sociais que acontecem no Brasil de hoje com o surgimento da nova classe média, seus estranhamentos e seus questionamentos em relação aos costumes e comportamentos da classe dominante.

\section{O mundo em transformação: observações} sobre os séculos XVIII e XIX

Os burgueses ganharam visibilidade entre os séculos XVIII e XIX com as revoluções Francesa e Industrial, mas a classe é mais antiga do que se imagina, remontando ainda à Europa Medieval. Desde o princípio, os burgueses eram uma classe dedicada ao comércio, que ganhou força quando a estrutura clássica dos feudos entrou em decadência. Ao explicar a origem da palavra "burguês" e sua disseminação pela Europa, Moretti (2014, p. 18) acaba também explicando um pouco da origem e da formação da classe:

A palavra bourgeois surgiu na França do século XI, sob a forma de burgeis, para designar os habitantes das cidades medievais (bourgs) que desfrutavam do direito legal de serem "livres e isentos da jurisdição feudal" (Robert). Em fins do século XVII, a acepção jurídica do termo - da qual emanou a ideia tipicamente burguesa de liberdade como "liberdade em relação a" - foi acompanhada de um sentido econômico que se referia, com peculiar série de negativas, a "alguém que não pertencesse nem ao clero nem à nobreza, não trabalhasse com seus braços e possuísse recursos independentes". Daquele momento em diante, embora a crono- 


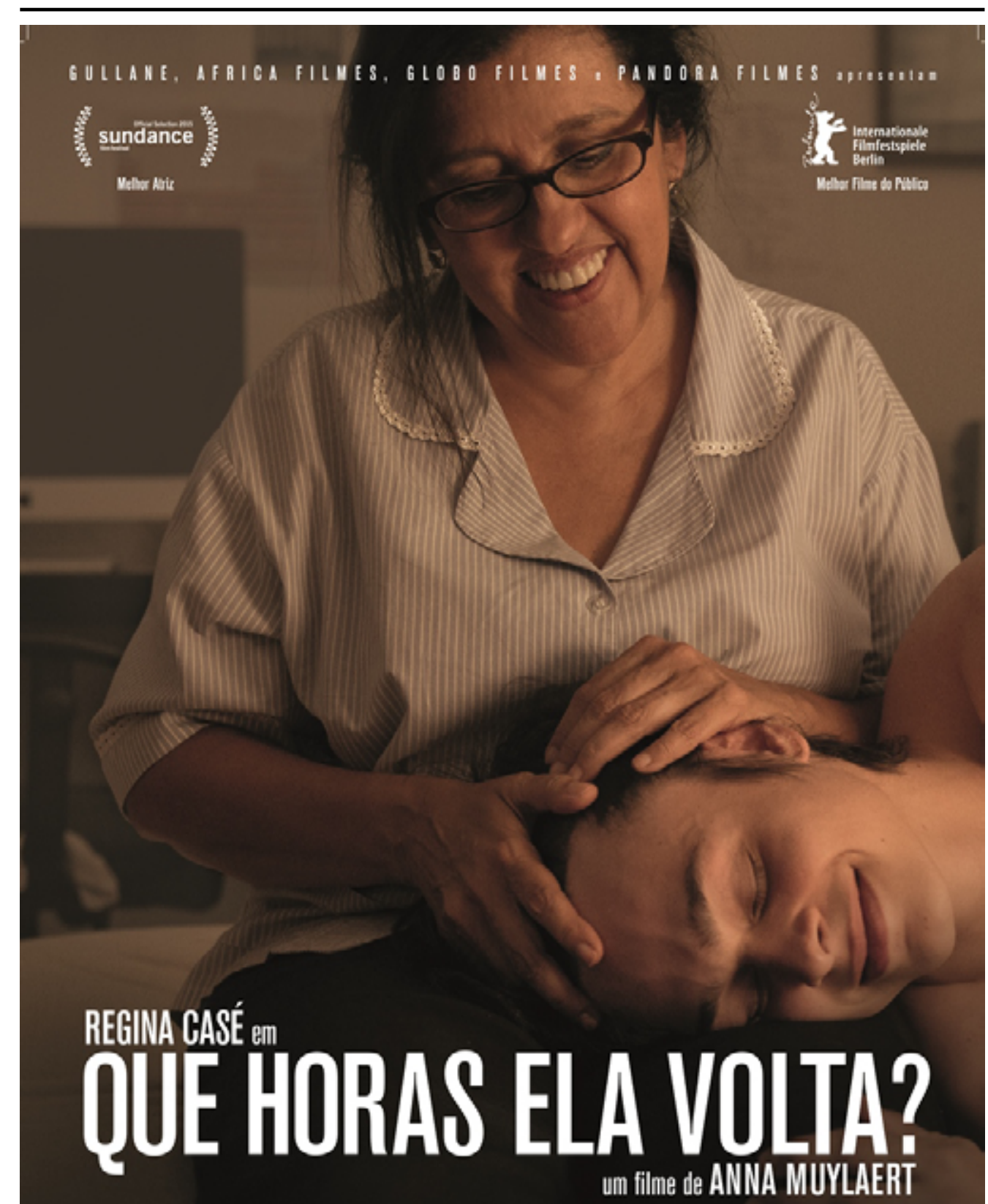

\section{MAR̃DILA TELES MUTARELLI JOELSAS ALBERGARIA}

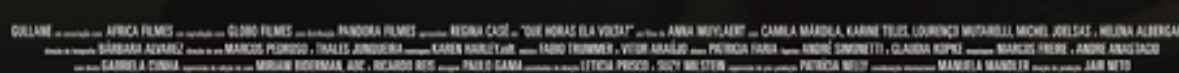

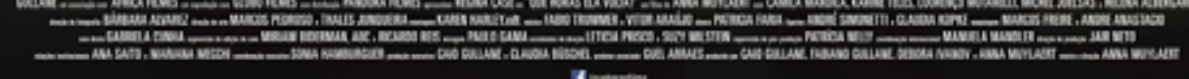

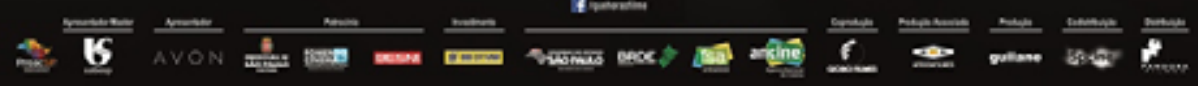

Figura 1: Cartaz de divulgação do filme. Fonte: Globo Filmes. logia e a semântica variassem de país para país, a palavra veio à tona em todos os idiomas europeus ocidentais, desde borgheses italiano até burgués espanhol, o burguês português, o Bürger alemão e o burger holandês.

Como Moretti (2014) afirma, ao explicar o surgimento do termo "burguês" em diversos países europeus, foi só a partir do final do século XVII que a estruturação da burguesia ganha mais força, mas ainda apenas esboçando certo poder político e alguma influência social. Cerca de um século depois, a força da burguesia já não podia ser ignorada, e esta foi a classe que protagonizou as duas revoluções - Francesa e Industrial - que provocaram mudanças relevantes nas estruturas sociais da Europa daquele período, com consequências em boa parte do mundo. Como indica Hobsbawm (2010, p. 98), “a França forneceu o vocabulário e os temas da política liberal e radical-democrática para a maior parte do mundo".

Dinheiro a burguesia já possuía - em maior ou menor grau, dependendo do segmento burguês considerado -, mas, dentro da lógica aristocrática do período, sua participação social e política era mínima; os burgueses mal eram reconhecidos como uma classe. Na França pré-revolucionária, por exemplo, em que as pessoas estavam divididas em Estados, os burgueses faziam parte do Terceiro Estado, junto com camponeses, trabalhadores braçais, operários, etc., enquanto clero e nobreza estavam divididos entre Primeiro e Segundo Estados, respectivamente, que ainda viviam à custa do trabalho árduo do resto da população. Ou seja, havia uma enorme parcela da sociedade profundamente insatisfeita com aquele sistema. 
Para promover a Revolução Francesa, os burgueses se aliaram aos camponeses, que representavam a grande maioria da população francesa daquele período - e cujas condições de vida tinham piorado por conta da crise econômica que a França enfrentava. Depois, uniuse a eles também a classe operária. Embora reunindo segmentos tão diferentes entre si, o que garantiu a coesão do movimento foi o compartilhamento de ideias, é claro, sob a liderança da burguesia esclarecida: "[...] um surpreendente consenso de ideias gerais entre um grupo social bastante coerente deu ao movimento revolucionário uma unidade efetiva. O grupo era a 'burguesia'; suas ideias eram as do liberalismo clássico" (Hobsbawm, 2010, p. 105).

Depois do início do movimento, os segmentos que antes eram parceiros começaram a se desentender entre si; ficou claro que seus objetivos não eram convergentes. A própria Declaração dos Direitos dos Homens e do Cidadão, publicada em 1789, nos momentos iniciais da Revolução, emblemática até hoje, representa "um manifesto contra a sociedade hierárquica de privilégios nobres, mas não um manifesto a favor de uma sociedade democrática e igualitária" (Hobsbawm, 2010, p. 106). Isso contribui para o cenário de instabilidade que a França passou a enfrentar, provocado pela própria revolução. Embora o regime monárquico tenha demorado mais a cair do que se imaginou em um primeiro momento, o movimento revolucionário já havia colocado a Europa em um caminho sem volta: "A ideologia do mundo moderno atingiu as antigas civilizações que tinham até então resistido as ideias europeias através da influência francesa" (Hobsbawm, 2010, p. 98).

A Revolução Francesa não foi o único movimento do tipo naquele período - o que demonstra a instabilidade que os regimes monarquistas europeus e seus sistemas econômicos enfrentavam -, mas foi o que provocou as consequências mais profundas, seja porque a França, depois da Rússia, era o mais populoso e poderoso Estado da Europa, seja porque foi uma revolução social de massa, de fato: "Seus exércitos partiram para revolucionar o mundo; suas ideias de fato o revolucionaram" (Hobsbawm, 2010, p. 99). A França não estava sozinha: na Inglaterra, também uma das maiores potências mundiais, uma parcela da burguesia ligada a atividades de manufatura deu início à Revolução Industrial:

De fato, a revolução industrial não foi um episódio com um princípio e um fim. Não tem sentido perguntar quando se "completou"; pois sua essência foi a de que a mudança revolucionária se tornou norma desde então. [...] Mas a revolução mesma, o "ponto de partida", pode provavelmente ser situada, com precisão possível em tais assuntos, em certa altura dentro dos 20 anos que vão de 1780 a 1800: contemporâneo da Revolução Francesa, embora um pouco anterior a ela (Hobsbawm, 2007, p. $60)$.

Como Hobsbawm (2007) coloca, a revolução industrial é um processo de aperfeiçoamento de técnicas de produção que perdura até hoje. No início, não houve um aumento no número de fábricas; a forma de produzir, antes totalmente manual, é que passou a contar com a ajuda de instrumentos. $O$ aumento na produção e o boom das indústrias só vieram algum tempo depois. As consequências desse processo foram significativas e começaram na Inglaterra, que havia se tornado "a 'oficina do mundo'" (Hobsbawm, 2007, p. 85), mas gradativamente passaram a alcançar diversos outros países.
E tanto a Grã-Bretanha quanto o mundo sabiam que a revolução industrial [...], cuja única lei era comprar no mercado mais barato e vender sem restrição no mais caro, estava transformando o mundo. Nada poderia detê-la. Os deuses e os reis do passado eram impotentes diante dos homens de negócios e das máquinas a vapor do presente (Hobsbawm, 2007, p. 85).

Com o aumento expressivo da produção, não havia mais como as indústrias dependerem do mercado consumidor existente, por isso, passaram a criar seu próprio mercado. $E$ isso foi feito de diferentes maneiras - desde a criação de necessidades por determinados produtos antes inexistentes até as pressões inglesas para o fim da escravidão pelo mundo, o que aumentaria o número de trabalhadores assalariados e, consequentemente, de consumidores para os produtos industrializados. 0 Brasil é um desses casos; além de fatores internos, a principal razão para a abolição da escravatura teria sido a pressão inglesa - de quem éramos dependentes economicamente.

Mas a revolução teve também um efeito colateral, algo, é claro, não desejado pela burguesia industrial: a estruturação da classe operária, do proletariado. As indústrias cresciam; por consequência, o proletariado também. Com ele, vieram os movimentos sociais, a luta por melhores condições de trabalho, a discussão em torno de modelos econômicos: "só a partir da década de 1840 é que o proletariado, rebento da revolução industrial, e o comunismo, que se achava ligado aos seus movimentos sociais - o espectro do Manifesto Comunista -, abriram caminho pelo continente" (Hobsbawm, 


\section{7, p. 58).}

O interessante é que, apesar dos embates, os industriais dependiam do proletariado, não só para o trabalho nas fábricas, como também para consumir os produtos que eles próprios produziam. Apesar dos salários miseráveis que comumente recebia, a classe também precisava consumir produtos industrializados para sobreviver nas grandes cidades, o que fez com que os operários acabassem representando um enorme mercado consumidor. Em comum, tanto a burguesia - industrial ou comercial - quanto o proletariado tinham o fato de representar novos segmentos da sociedade, tipos sociais surgidos ao longo das duas revoluções de que tratamos aqui.

O homem burguês: causa e

\section{consequência das transformações}

O mundo já se reconfigurava quando as revoluções Francesa e Industrial aconteceram. É certo que ambos os movimentos são marcos consideráveis na história mundial, mas são reflexos das transformações sociais, culturais e econômicas que já estavam em curso. A estrutura clássica das monarquias europeias não começou a apresentar problemas somente no fim do século XVIII; algum tempo antes, já apresentava sinais de esgotamento. Considerando sua onerosa organização econômica, é curioso que essas monarquias absolutistas tenham existido por um tempo significativo, até que as contas, baseadas em gastos indiscriminados por parte da nobreza e quase nenhuma produção de riqueza, passaram a não mais fechar.

Segundo Elias (2001, p. 86), o que prevalecia na Europa pré-revolucionária era o ethos do consumo, baseado no chamado "consumo de prestígio", ou seja, cada posição social implicava certas obrigações de gastos, como o autor coloca, impunha uma "obrigação de prodigalidade". A economia, no sentido de poupar, era tratada pela aristocracia com desprezo, como "virtude de gente pequena" (Elias, 2001, p. 86). Os nobres se viam na obrigação de gastar em função do status que possuíam ou almejavam:

[...] o mero asseguramento da posição social de uma família - assim como uma melhora da aparência e do êxito na sociedade - dependem da capacidade de tornar os custos domésticos, o consumo, as despesas em geral, dependentes em primeira instância do nível social, do status ou prestígio possuído ou almejado (Elias, 2001, p. 86).

A burguesia desejava reconhecimento e ascensão social, mas sua forma de conseguir tudo isso estava distante da praticada pela nobreza. Segundo Elias (2001), os burgueses fundaram um novo ethos econômico e social, em primeiro lugar, baseado na produção de riqueza por meio do trabalho - diferentemente da aristocracia, que vivia de rendimentos das posses de família, transmitidas por herança às gerações -, em segundo lugar, baseado no ato de poupar. Para a burguesia, "a garantia da posição familiar alcançada e sobretudo a garantia do êxito social, da obtenção de mais status e prestígio, depende de uma estratégia de ganhos e despesas a longo prazo" (Elias, 2001, p. 85). A estratégia econômica dos burgueses contribuiu de forma determinante para sua consolidação e perenidade em relação à nobreza.

De forma alguma, isso significava que os burgueses não gastavam - pelo contrário. Primeiramente, naquele período - e, vale ressaltar, até hoje -, são os padrões e estilos de vida das classes mais elevadas que tentam ser imitados, ou buscados, por aqueles que estão abaixo delas: "[...] todos os padrões de consumo derivam, por gradações imperceptíveis, dos usos e hábitos de raciocínios dos da classe social e pecuniária mais elevada" (Veblen, 1965, p. 50). Tanto que Hobsbawm sinaliza que a decadência das sociedades aristocráticas na Europa pós-revolucionária não significou o fim de seus valores:

O fim da sociedade aristocrática também não significou o fim da influência aristocrática. As classes em ascensão naturalmente tendem a ver os símbolos de sua riqueza e poder em termos daquilo que seus antigos grupos superiores tinham estabelecidos como os padrões de conforto, luxo e pompa (Hobsbawm, 1988, p. 203).

Em segundo lugar, em sociedades industriais é norma consumir; não há como mantê-las de outra forma. Como "as características do sistema convencional de consumo não mudam facilmente" (Veblen, 1965, p. 36), nesse período, a compra e a exibição de bens se mantêm, como nas sociedades aristocráticas, como prova de riqueza e forma de diferenciação entre as classes: "por ser o consumo dos bens de maior excelência prova de riqueza, ele se torna honorífico; reciprocamente, a incapacidade de consumir na devida quantidade e qualidade se torna uma marca de inferioridade e demérito" (Veblen, 1965, p. 37).

Os burgueses, portanto, consumiam, embora de forma diferente da nobreza. As famílias burguesas deveriam submeter "as despesas às receitas, mantendo sempre que possível o consumo diário abaixo do nível do que se recebe, de modo que a diferença constitua uma economia a ser investida na expectativa de ganhos maiores no futuro" (Elias, 2001, p. 85). Esse com- 
portamento não era próprio da nobreza, que sequer possuía vencimentos a partir dos quais poderia planejar seus gastos. Essa teria sido a grande mudança promovida pela nova classe. Os burgueses substituíram a vida de ócio ostensivo levada pela nobreza por atividades geradoras de riqueza e passaram, ainda, a desaprovar qualquer atividade que não pudesse gerar rendimentos em dinheiro: "O efeito sobre as atividades produtivas importantes do homem consiste, portanto, em dirigi-las, com o propósito bem definido, para a maior aquisição de riquezas possível, e para a desaprovação do trabalho que não produza lucros pecuniários" (Veblen, 1965, p. 53).

Os desperdícios da nobreza ociosa, em oposição à produção e economia dos burgueses, geraram uma situação curiosa: uma classe de fidalgos com sangue nobre empobrecidos e outra, enriquecida sem título algum de nobreza, eram os parvenus (Hobsbawm, 1988, p. 205), ou "novos ricos". Foi esse o caminho para a estruturação de uma classe média entre os séculos XVIII e XIX. Embora a condição de medianidade fosse exatamente $o$ que o burguês quisesse superar, não havia termo melhor que "classe média" para definir um segmento social que "não era um camponês nem um servo, mas também não era um nobre" (Wallerstein apud Moretti, 2014, p. 16). Além disso, essa noção trazia uma possibilidade maior de mobilidade entre as classes (o que era almejado pelos burgueses) do que em uma sociedade dividida por segmentos herméticos, que lembravam muito mais castas. Moretti (2014, p. 21) explica:

Embora "classe média" e "burguesia" denotassem exatamente a mesma realidade social, criavam em torno delas associações muito diversas [...] "baixa", "média" e "alta" constituíram um continuum em que a mobilidade era muito mais fácil de imaginar do

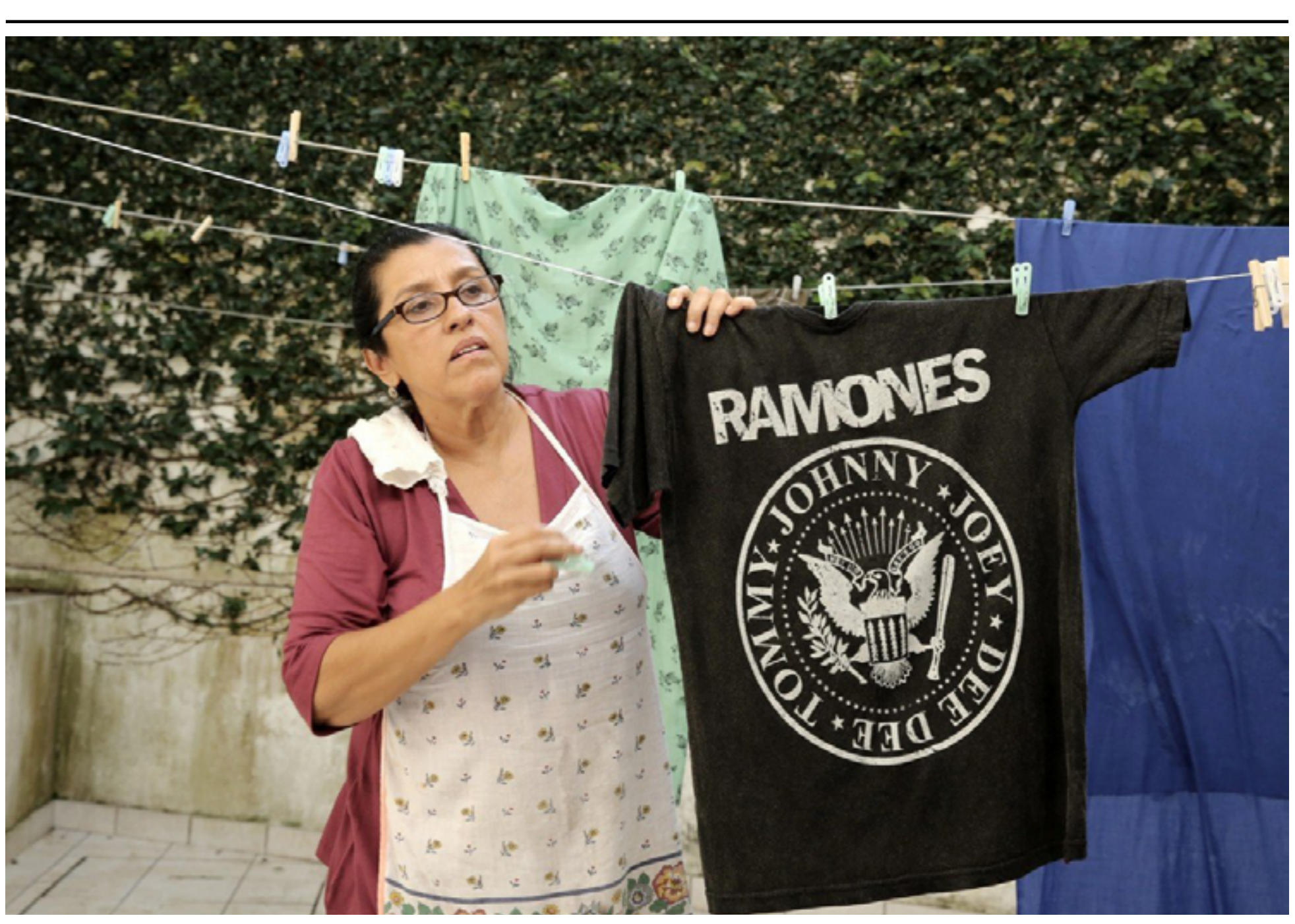

Figura 2: Frame do filme Que horas ela volta?. Fonte: Flickr.

53 PORTO ALEGRE | v. 22 | n. 37 | 2017| pp. 48-58 Sessões do Imaginário 
que entre categorias incomensuráveis - "classes" - como campesinato, proletariado, burguesia ou nobreza. E assim, a longo prazo, o horizonte simbólico gerado pela "classe média" funcionou extremamente bem para a burguesia [...].

Um olhar sobre as tensões entre classes em Que horas ela volta?

Mais de dois séculos depois das revoluções Francesa e Industrial, ambas seguem como importantes marcos da história mundial, em especial porque significaram a passagem para um novo momento: a modernidade. Entre as grandes marcas da modernidade está a desintegração das antigas estruturas, a falta de unidade, ou "unidade paradoxal", como propõe Berman (2008, p. 9): "uma unidade de desunidade: ela nos despeja a todos num turbilhão de permanente desintegração e mudança, de luta e contradição, de ambiguidade e de angústia". No mesmo sentido, a célebre frase de Marx ilustra bem o que é o momento moderno: tudo o que é sólido desmancha no ar. É claro que hoje já não vivemos o contexto revolucionário europeu de outrora, mas parecemos ainda levar a cabo os processos de transformação e desintegração que, portanto, seguem como marcas da modernidade:

Existe um tipo de experiência vital - experiência de tempo e espaço, de si mesmo e dos outros, das possibilidades e perigos da vida - que é compartilhado por homens e mulheres em todo o mundo, hoje. Designarei esse conjunto de experiências como "modernidade". Ser moderno é encontrar-se em um ambiente que promete aventura, poder, alegria, crescimento, autotransformação e transformação das coisas em redor - mas ao mesmo tempo ameaça destruir tudo o que temos, tudo o que sabemos, tudo o que somos (Berman, 2008, p. 9, grifo nosso).

Ao longo do século XIX, com as revoluções, o estabelecimento da modernidade e todas as mudanças consequentes desses eventos, a nobreza sairia de cena e os burgueses se tornariam a classe dominante. Como coloca Moretti (2014, p. 13): "[...] no decurso do século XIX, a figura sincrética da burguesia proprietária e instruída veio à tona em toda a Europa ocidental, [...] fortalecendo suas qualificações como uma possível nova classe dominante" - possibilidade esta que se confirmou. Na direção oposta, estabeleceu-se a classe operária. Estavam, portanto, dadas as forças que iriam se contrapor, mas estabelecer uma relação de profunda dependência ao longo daquele período.

É considerando a burguesia como a classe dominante ainda hoje que se pretende traçar um paralelo entre o que se viveu no passado, apresentado aqui com base em autores de diferentes correntes teóricas, e o que se vive hoje no Brasil. Em primeiro lugar, faz-se importante ressaltar que temos consciência que importantes mudanças sociais e econômicas aconteceram no intervalo de tempo considerado; os próprios termos "burguesia" e "proletariado", por exemplo, caíram em relativo desuso. No entanto, uma das condições primordiais que torna possível a comparação proposta está no fato de que - novamente considerando o contexto brasileiro -, assim como no passado a ascensão da burguesia incomodou a aristocracia, hoje, a ascensão de uma nova classe média incomoda a atual burguesia, que se estabeleceu como classe dominante desde a passagem para a modernidade.
Essa transformação, que gera incômodo em uma parcela da população, pode ser observada de diferentes maneiras na realidade vivida, seja por meio de matérias jornalísticas ou comentários cotidianos. Nosso foco, aqui, é examinar especificamente uma representação ficcional desse debate, por meio do filme nacional Que horas ela volta? (Anna Muylaert, 2015). A produção teve repercussão internacional e chegou a ser cotada para representar o Brasil no Oscar 2016. O filme foi dirigido por Anna Muylaert e tem Regina Casé no papel principal. A atriz vive a empregada doméstica pernambucana Val, que se muda para São Paulo em busca de melhores condições de vida para a filha Jéssica (Camila Márdila). Val vive por 13 anos na casa da família para a qual trabalha, até que a filha decide fazer vestibular na capital paulista e morar com a mãe. O ambiente específico da casa onde se desenrola a história tem o poder de resumir aspectos fundamentais próprios da sociedade atual.

Em primeiro lugar, é fundamental enfatizar que não é objetivo deste estudo analisar os critérios econômicos que levam à caracterização da "nova classe média" ou da "classe C", mas, sim, colocá-la em uma condição de segmento social ascendente, tornando possível a comparação com outros momentos já vividos no mundo ocidental. A análise a partir de uma perspectiva histórica também tende a se mostrar rica, pois, conforme Elias (2001, p. 93) argumenta, para entender melhor o presente é preciso se voltar ao passado:

Aprendemos a entender melhor o contexto social de nossa própria vida quando nos aprofundamos no de pessoas pertencentes a uma outra sociedade. A investigação da sociedade de corte revela, com mais clareza do que se estudássemos apenas 


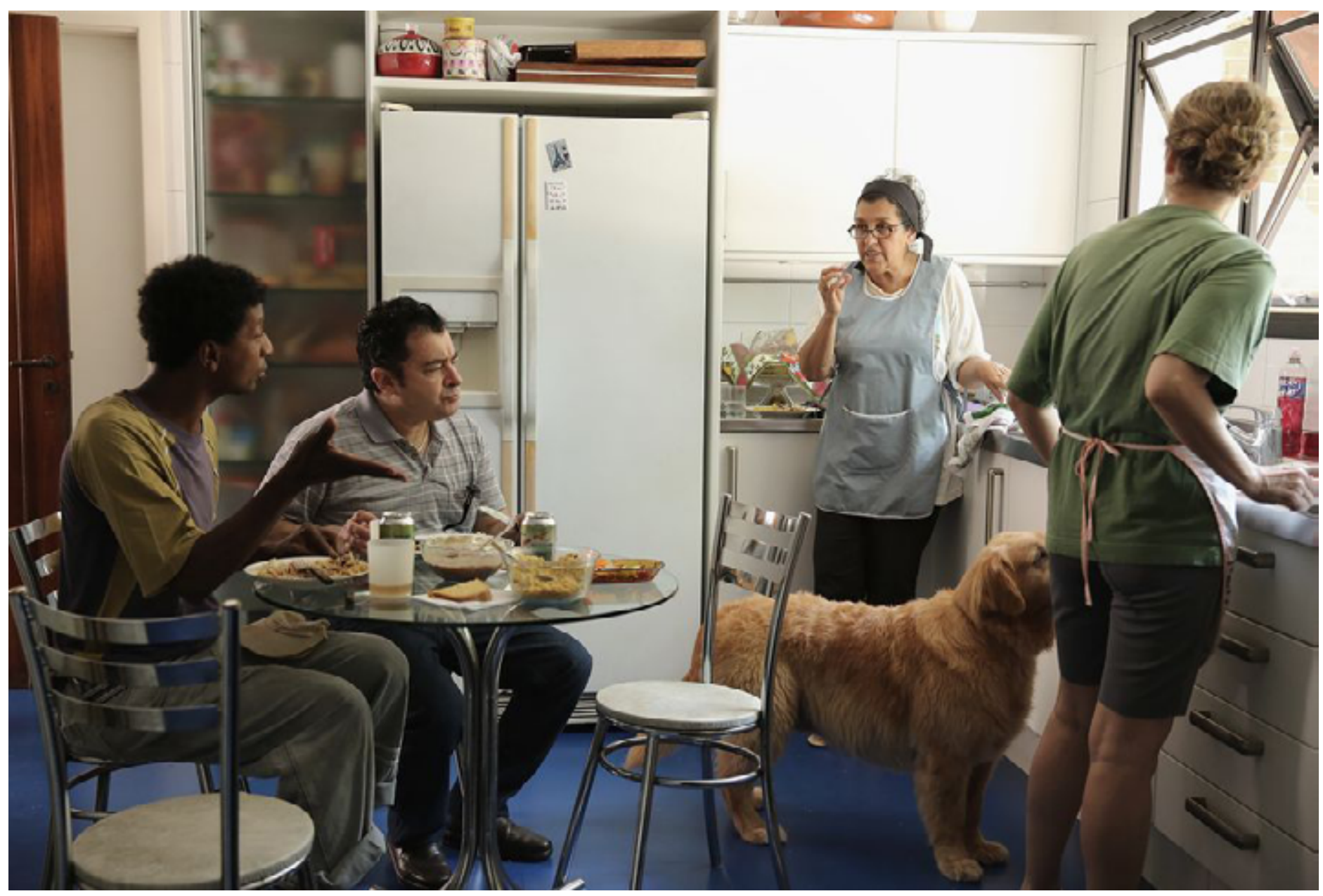

Figura 3: Frame do filme Que horas ela volta?. Fonte: Flickr.

nossa própria sociedade, que nossa escala de valores constitui um elo na corrente de interdependên cias a que estamos submetidos.

Um dos aspectos que chama a atenção no filme, de imediato, é exatamente a condição de transformação constante que marca a modernidade. Jéssica e sua mãe têm concepções absolutamente diferentes sobre o trabalho doméstico. Para Val, dormir em um "quartinho nos fundos", como a filha coloca, da casa onde trabalha e se dedicar integralmente àquela família é um comportamento não só aceitável como natural. Para Jéssica, não. Há 13 anos sem ver a mãe, ela traz uma série de questionamentos àquele modelo de emprego e às condições de vida e trabalho impostas à mãe. Apesar dos poucos anos que separam as duas, suas ideias sobre alguns assuntos diferem fundamentalmente, o que bem ilustra a frase de Marx (apud Berman, 2008, p. 15) sobre o que se poderia chamar de instabilidade própria da modernidade: "todas as novas relações se tornam antiquadas antes que cheguem a se ossificar".

Um dos pontos centrais do filme é exatamente esse: mostrar como, em um intervalo de tempo não muito extenso, noções absolutamente novas de emprego doméstico ascenderam. Como herança da escravidão, as relações entre empregadas domésticas - no feminino, é importante ressaltar - e seus patrões historicamente é bastante precária; a própria legislação trabalhista era falha em muitos sentidos. Como um fenômeno recente, uma parcela da sociedade passou a questionar a informalidade do campo, promovendo mudanças no cenário, inclusive legalmente (Lourenço; Jungmann, 2015). Nesse sentido, Jéssica é a figura central do filme, pois representa, de forma notável, a inquietação e o novo.

Os questionamentos de Jéssica são retratados no filme de diferentes formas. Uma das cenas marcantes, nesse sentido, é quando as duas estão voltando de ônibus do aeroporto. Jéssica demora a entender que a mãe mora no serviço, tamanho é seu estranhamento. Val diz várias vezes que os patrões estão ansiosos para conhecê-la e a filha insiste que prefere ir ao trabalho da mãe depois, até que compreende a situação: "Como assim tu mora lá, Val? Tu mora no quartinho dos fundos da casa deles! [...] Pelo amor de Deus, Val, não tô acreditando nisso, não. Tu tá me levando pra casa dos outros!", exclama a personagem.

Em outro diálogo, a jovem pergunta à mãe se ela nunca entrou na piscina da casa, ao que Val responde: "e eu vou nadar na piscina da casa dos outros?"; e dá, ainda, fortes recomendações à filha para que não use a piscina, que aquilo "não é para o seu bico", mesmo que alguém a convide. Jés-

55 PORTO ALEGRE | v. 22 | n. 37 | 2017| pp. 48-58 Sessões do Imaginário 
sica, mais uma vez, demonstra claramente sua insatisfação. No entanto, o que a torna especial é o fato de não só questionar ou se mostrar insatisfeita, mas de representar, de fato, a mudança. Em relação às duas situações aqui expostas, Jéssica subverte a ordem: depois de conversar com Carlos (Lourenço Mutarelli), o patrão, sai do quartinho que ia dividir com a mãe e vai para uma suíte desocupada reservada a hóspedes; quanto à piscina, a personagem não tarda para fazer uso dela com Fabinho (Michel Joelsas), filho dos patrões. Em duas cenas simples, existe inquietação, subversão e questionamento dos padrões morais e das estratificações sociais.

Essa atmosfera - de agitação e turbulência, aturdimento psíquico e embriaguez, expansão das possibilidades de experiência e destruição das barreiras morais e dos compromissos pessoais, auto-expansão e autodesordem, fantasmas na rua e na alma - é a atmosfera que dá origem à sensibilidade moderna (Berman, 2008, p. 12).

Se Jéssica representa muito bem a classe que ascende, Bárbara (Karine Teles), a patroa, representa com maestria a classe dominante, ou seja, a burguesia, que passou a ocupar o lugar outrora ocupado pela aristocracia. De diversas formas, Bárbara tenta demarcar as diferenças que acredita existir entre as classes sociais a que cada uma pertence e reforçar sua superioridade, pois supõe "que as barreiras legais, e todas as outras que separam os diferentes grupos de elite de sua sociedade, permanecem intocadas" (Elias, 2001, p. 87). Existe uma cena do filme em que essa tentativa de delimitar o espaço de cada classe chega a ser literal. Depois de gerar muito incômodo, a patroa pede a Val para que impeça a filha de transitar pela casa. Bastante irrita- da, ela chega a afirmar: "pode não parecer, mas essa casa ainda é minha"; na sequência, dá a ordem: "enquanto ela [Jéssica] tiver aqui, queria te pedir pra deixar ela da porta da cozinha pra lá". Para Bárbara, a menina era uma ameaça a ela e a sua posição social.

Todo o sistema era carregado de tensões. Era impregnado de inumeráveis rivalidades por parte dos homens que procuravam proteger suas posições, demarcando-as contra os níveis inferiores [...]. Enquanto havia infindáveis tensões e conflitos em torno de determinadas regalias, a ameaça às regalias como tais significava, para a maioria dos privilegiados, uma ameaça genérica àquilo que dava sentido e valor às suas vidas (Elias, 2001, p. 95).

O que o autor fala acima, sobre a chamada sociedade de corte, pode também ser aplicado às sociedades atuais. As tentativas de manutenção exclusiva de privilégios e "luxos" por Bárbara são constantes. Ela se incomoda quando Jéssica entra na piscina, chegando a mandar esvaziá-la para limpeza; não gosta que a menina tome o sorvete, mais caro, que compra para Fabinho (Val sempre foi proibida de tomá-lo); e não esconde sua profunda insatisfação quando a filha da empregada passa a ocupar uma suíte de sua casa. É como se as regalias fossem apenas para os ricos; aos pobres, esse consumo do "supérfluo" sofre interdição: "o consumo de artigos de luxo, no seu verdadeiro sentido, é consumo que visa o conforto do próprio consumidor, é, portanto, atributo do senhor" (Veblen, 1965, p. 36) - e somente dele, é importante enfatizar.

No entanto, nenhuma das situações acima incomodou mais Bárbara do que a pontuação elevada que Jés- sica obteve no vestibular, em oposição à de seu filho os dois concorriam ao mesmo curso. Quando Val conta a novidade, a patroa, mais uma vez, tenta diminuir as conquistas da jovem: “Não tô acreditando, incrível, né... [...] Val, aqui, não fica muito animada, isso foi a primeira fase, ainda vai ter outra prova, a segunda fase é muito mais difícil". Posteriormente, a menina obtém a aprovação, enquadrando-se nas ideias de self-made-man trabalhadas por Hobsbawm (1988, p. 207): “Eles eram homens que se fizeram por si mesmos ou, pelo menos, sendo de origem modesta, deviam pouca coisa ao nascimento, à família ou a uma educação formal superior".

Jéssica reúne todas as características de self-made -man tratadas pelo autor acima: sua origem é humilde, pouco devia à condição social ou econômica de sua família e, agora, se poderia cursar uma universidade, foi por seu próprio esforço e dedicação. A personagem ilustra que, hoje, o carreirismo individual (Hobsbawm, 1988) segue como um dos mais fortes valores sociais aspecto que passou a marcar as sociedades burguesas no período pós-revolucionário: "a realização crucial das duas revoluções foi, assim, o fato de que elas abriram carreiras para o talento ou, pelos menos, para a energia, a sagacidade, o trabalho duro e a ganância" (Hobsbawm, 1988, p. 211).

No fim do filme, há uma cena em que a mobilidade social está simbolicamente representada. Depois de receber a notícia da aprovação da filha, Val entra na piscina, parcialmente cheia - por conta da limpeza que estava sendo feita -, conseguindo molhar parte da perna. Ainda que tudo seja feito de forma bastante silenciosa, a atitude da empregada é emblemática, pois significa uma subversão: a piscina sempre tinha sido a ela veta$\mathrm{da}$, assim como a possibilidade de ingresso em um curso superior por muito tempo, no Brasil, havia sido qua- 
se que exclusiva da classe dominante. Mais uma vez, aplicamos o pensamento de Hobsbawm (2007, p. 237) à atualidade: "a mobilidade social poderia de fato colocar numerosas pessoas dentro de uma situação histórica inteiramente nova para desempenhar papéis sociais novos (e superiores) [...]".

A possibilidade de construir uma carreira, de ganhar dinheiro e alguma importância e influência social a partir do trabalho duro, acabou significando também a possibilidade de mobilidade social, presente fortemente na sociedade brasileira retratada no filme. $O$ que Hobsbawm (1988, p. 211) explica de um período passado, mais uma vez, pode ser aplicado ao que se vive hoje: "como eram extraordinárias as oportunidades, como estava afastado do século XIX o estático ideal hierárquico do passado!". O novo cenário de mobilidade social que se configura a partir da Revolução Francesa só é permitido pelas também novas possibilidades de trabaIho e carreira proporcionadas pela Revolução Industrial. Ou seja, fazendo referência às reflexões de Hobsbawm, as duas revoluções são movimentos complementares e concomitantes, que exercem influência um sobre o outro. Quando as transformações sociais que se dão com o surgimento da nova classe média na atualidade são abordadas, como se objetivou fazer aqui a partir do filme em questão, evidencia-se uma comparação possível entre a contemporaneidade e o ocorrido durante as revoluções que tiveram início dois séculos atrás.

Que horas ela volta? é um filme que traz simbologia em diversas cenas e diálogos e, consequentemente, possibilita interpretações bastante ricas. Mostra-se um objeto interessante de análise não só da produção cinematográfica brasileira recente, mas das transformações socioeconômicas do país, por permitir traçar o paralelo aqui proposto entre passado e presente, provando que há mais semelhanças do que poderíamos supor em um primeiro momento, apesar de dois séculos separarem a Era das Revoluções (Hobsbawm, 2010) da atualidade e do ambiente nacional. A produção se prova, ainda, significativa por indicar que a modernidade está bastante viva, pelo menos nos termos apontados por Berman (2008). A relação entre personagens é turbulenta; Jéssica representa o desmanche ou a desintegração de tudo o que até então havia parecido bastante sólido para Bárbara.

O que acontece dentro da casa onde se passa o filme, localizada no Morumbi, em São Paulo, bairro de classe média alta, representa todo o cenário de mudança social em curso já algum tempo, do qual observamos diferentes consequências de acordo com o momento histórico vivido. Que horas ela volta? propõe, conforme explicou Berman (2008, p. 10) sobre o que acontecia dois séculos atrás, que seguimos em "uma era que desencadeia explosivas convulsões em todos os níveis de vida pessoal, social e política".

\section{Considerações finais}

Reconhecemos que encontrar equivalências entre o que se viveu mais de duzentos anos atrás na Europa e o que se vive hoje no Brasil, como o proposto neste artigo, é um desafio arriscado. Não são poucas as chances de se perder ao longo da história ou de as comparações ficarem frouxas ou forçadas. Para evitar que isso acontecesse, recorremos às análises sociológicas e históricas de autores como Berman (2008), Elias (2001), Hobsbawm $(1988,2007)$, Moretti (2014) e Veblen (1965). Suas ideias, alinhadas entre si e, em muitos sentidos, complementares, reforçam a possibilidade de examinarmos, à luz da história, as representações de classe em produções cinematográficas contemporâneas a partir dos lugares sociais ocupados por personagens - representantes típicos de determinados perfis - e das tensões entre eles instauradas. Mais uma vez, é importante enfatizar que a escolha dos autores foi a partir do viés sociológico e histórico - e não econômico - que este artigo adota; por isso, não há qualquer tentativa de classificação econômica da chamada nova classe média.

Acreditamos que a comparação entre passado e presente, por meio do filme Que horas ela volta?, retrata as transformações socioculturais com as quais a sociedade brasileira se defronta hoje. Também se objetivou lançar um outro olhar ao filme, deslocando Val do centro da análise e colocando, neste lugar, Jéssica, e, em segundo plano, Bárbara. Essa é apenas uma das formas de observar a produção, que se abre para muitas outras possibilidades de estudo. Há, por exemplo, possibilidades de se observar a mudança gradativa de comportamento de Val a partir das conquistas da filha, em um regime de deslocamento das representações e das identificações; é como se ela se aproximasse cada vez mais de uma condição antes vetada.

Outro personagem que não exploramos aqui e a quem se pode dedicar uma análise minuciosa é Carlos, marido de Bárbara, que se apresenta como uma figura de transição, aceitando mais facilmente o novo cenário que se impõe. Ele se envolve, ainda, emocionalmente com Jéssica, que parece não corresponder a seus sentimentos. Aliás, a questão afetiva também é explorada no filme, no sentido de mostrar a complexidade das relações de trabalho doméstico no Brasil - este é mais um viés a partir do qual o filme pode ser estudado. Val considera e trata Fabinho como seu filho, e o menino, muitas vezes, mostra se sentir mais à vontade com a empregada do que com sua própria mãe, aceitando melhor os conselhos e os carinhos da primeira. A análi- 
se da obra sugere outras possibilidades de aprofundamento - a partir de linhas como os estudos de linguagem, as teorias do audiovisual e a análise do discurso, que lançam luz sobre as problemáticas da representação social, dos estigmas e da questão da identidade, entre outros aspectos. Se, conforme considera Elias (2001, p. 90), "muito do que se diz [...] acerca da sociedade de corte sugere analogias com as sociedades de nações industrializadas, facilitando uma compreensão conceitual mais precisa de semelhanças e diferenças estruturais", Que horas ela volta? representa, nesta análise, um caminho de abertura para estudos futuros sobre os modos de representação da luta de classes contemporânea no audiovisual brasileiro.

\section{Referências}

BERMAN, Marshall. Tudo que é sólido desmancha no ar. São Paulo: Cia. das Letras, 2008.

ELIAS, Norbert. A sociedade de corte. Rio de Janeiro: Zahar, 2001.

Flicker. Photos. Figura 2. Disponível em: $<$ https://www. flickr.com/photos/sescsp/23369608621 >. Acesso em: 29 maio 2017.

Flicker. Photos. Figura 3. Disponível em: <https://www. flickr.com/photos/Imaq_cartelesdecine/19320392703>. Acesso em: 29 maio 2017.

Globo Filmes. Figura 1. Disponível em: <http://globofilmes.globo.com/filme/quehoraselavolta $>$. Acesso em : 05 setembro 2017.

HOBSBAWM, Eric. A era do capital (1848-1875). São
Paulo: Paz e Terra, 2007.

A era das revoluções (1789-1848). São Paulo: Paz e Terra, 1988.

Paz e Terra, 2010.

MORETTI, Franco. 0 burguês: entre a história e a literatura. São Paulo: Três Estrelas, 2014.

LOURENÇO, Luana; JUNGMANN, Mariana. Dilma sanciona nova lei para empregado doméstico; veja o que mudou. UOL. 2 jun. 2015. Disponível em: <http:// economia.uol.com.br/empregos-e-carreiras/noticias/ redacao/2015/06/02/dilma-sanciona-nova-lei-para -empregado-domestico-veja-o-que-mudou.htm\#comentarios>. Acesso em: 31 maio 2017.

VEBLEN, Thorstein. A teoria da classe ociosa: um estudo econômico das instituições. São Paulo: Pioneira, 1965.

\section{Referências audiovisuais}

MUYLAERT, Anna. Que horas ela volta? [Filme]. Produção de Guel Arraes, Claudia Büschel, Caio Gullane, Fabiano Gullane, Débora Ivanov, Gabriel Lacerda, Anna Muylaert, Jair Neto e Gabriela Tocchio, direção de Anna Muylaert. Rio de Janeiro, Globo Filmes, Gullane Filmes e África Filmes, 2015. 112min. Colorido. Sonoro.

\section{Notas}

1 Doutoranda do Programa de Pós-Graduação em Comunicação e Práticas de Consumo da Escola Superior de Propaganda e Marketing (ESPM-SP). Professora do
FIAM-FAAM (Jardim Guedala, Centro Universitário FIAM-FAAM - Ana Rosa. Rua Vergueiro, 2009, Paraíso - São Paulo, Brasil, CEP: 04.101-905). E-mail: mayaraluma@gmail.com. 